\title{
Prescription Opioid Misuse: Effective Methods for Reducing the Epidemic
}

Xiaofan Li, M.D., Ph.D. ${ }^{1,3}$ Daryl Shorter, M.D. ${ }^{2,3, *}$ Thomas Kosten, M.D. ${ }^{2,3}$

\author{
Address \\ ${ }^{1}$ Harris Health - Ben Taub General Hospital, 1504 Taub Loop, Houston, TX 77030, \\ USA \\ ${ }^{*}, 2$ Michael E. DeBakey VA Medical Center, 2002 Holcombe Blvd, Houston, TX \\ 77030, USA \\ Email: shorter@bcm.edu \\ ${ }^{3}$ Menninger Department of Psychiatry and Behavioral Sciences, Baylor College of \\ Medicine, One Baylor Plaza, Houston, TX 77030, USA
}

Published online: 16 April 2015

(C) Springer International Publishing AG (outside the USA) 2015

This article is part of the Topical Collection on Substance Use Disorders

Keywords Prescription opioid abuse · Abuse-deterrent formulations · Oxycodone - Buprenorphine

\section{Opinion statement}

Prescription opioid misuse has been a significant epidemic during the past decade. Formulations of prescription opioids with different mechanisms of abuse-deterrence have been developed or are currently under development. Given that these medications are substantially more difficult to use in an illicit fashion and minimize the potential for euphoria and/or create an aversive experience when over-ingested, they represent an important next step in pharmacological innovation. Immediate decreases in nonmedical use and in associated overdose mortality and adverse events have been observed after a highly abused opioid, OxyContin, was changed into an abuse-deterrent formulation. However, this reduction in 0xyContin use may have simply shifted the drug of choice towards other more easily misused opioids, suggesting that a change in formulation alone will not be sufficient in controlling the epidemic. To control prescription opioid misuse requires treating populations with opioid use disorder and preventing the development of opioid abuse or dependence in unaffected populations. Buprenorphine with naloxone has been designed as an abuse-deterrent formulation, while also demonstrating significant efficacy in treating opioid use disorder. Thus, the dissemination of buprenorphine treatment can be a helpful step in reducing the current epidemic. Other strategies to reduce the epidemic include limiting the availability of leftover prescription opioids through drug take back programs, monitoring physician prescriptions through state prescription 
monitoring programs, and implementing evidence-based practices in pain management. Increased referral of patients with chronic nonmalignant pain to comprehensive pain rehabilitation programs can also reduce healthcare utilization while improving patient outcomes. Also, routine screening for prescription misuse and referral for addictions treatment must become a standard practice in order to ensure patient safety and create early opportunities for intervention.

\section{Introduction}

The early twenty-first century has seen a dramatic rise in the use, misuse, dependence upon, and medical complications arising from prescription opioid medications. According to the US Center for Disease Control (CDC), sales of prescription opioids in 2010 were more than four times those in 1999, increasing to approximately $7.1 \mathrm{~kg}$ per 10,000 populations, equivalent to $710 \mathrm{mg}$ per person in the USA [1]. Similarly, the overdose mortality in 2008 almost quadrupled the rate observed in 1999. The admission rate into substance abuse treatment for opioid use disorders in 2009 was almost six times the rate in 1999, and the estimated emergency department (ED) visits from nonmedical use of opioid analgesics increased $111 \%$ during 2004-2008 (from 143,500 to 271,700 visits) [1, 2]. According to the National Survey on Drug Use and Health (NSDUH), in 2013, there were an estimated 4.5 million current (past month) non-medical users of prescription pain relievers ( $1.7 \%$ of US population), a slight decrease from the previous year's estimate of 4.9 million current users (1.9\%); however, opioids remain second only to cannabis in rates of illicit use and is far above the prevalence of other illicit substances [3]. Non-medical use of prescription opiates among adolescents and young adults also represents a significant problem. Among adolescents, $68 \%$ of intentional exposures to prescription medications were identified to be opioids, and about one-third were suspected suicide attempts, resulting in a mortality rate of $0.1 \%$ [4]. A similar trend in use was identified among college students, with $48 \%$ of this population reporting nonmedical use of pain relievers [5]. Sources of opioid prescriptions illicitly obtained and used by adolescents include, in descending order: friends and family through purchase or theft, a single physician, drug dealers, and the internet [6]. Interestingly, evidence suggests that among those diagnosed with opioid use disorder who do not themselves have a medication prescription, approximately half obtain medications from a person with a prescription, suggesting an even greater role of physician as source than previously suspected [7].

Other factors associated with addiction liability of prescription opioids include the individual's underlying motivation for use as well as pharmacologic factors such as route of administration. For example, McCabe et al found that persons who took leftover medications from their own previous prescriptions were using primarily to relieve physical pain, while persons obtaining medications from other sources were more likely to demonstrate prescription opioid abuse and other substance use behaviors [8]. Ultimately, this raises concerns regarding continued access to leftover medications as well as the need to encourage safe disposal of unused prescription medications. In a separate study, Butler et al found the abuse potential of specific opioids was associated with the user's preferred route of administration. The investigators found that patients entering substance abuse treatment $(N=59,792)$ most frequently abused hydrocodone and oxycodone immediate-release (IR) and extended-release (ER), with oxycodone ER carrying the greatest risk for abuse. The investigators also found that route of administration differed between the medications, with hydrocodone being most likely to be abused orally, oxycodone primarily by nasal route (i.e., snorting or inhalation), and morphine most likely being used intravenously [9•], replicating their findings from an earlier study [10]. Importantly, non-oral routes of administration appear to be a progression from oral ingestion and have been associated with a longer duration of abuse [11-14]. 


\section{Abuse-deterrent formulations}

Given the widespread concerns regarding misuse and diversion of prescription opioid medications, various abuse-deterrent formulations of these medications with different mechanisms have been released or are currently under development.

\section{Tamper-resistant formulations}

One method of achieving abuse-deterrence is through employment of tamperresistant technologies, since prescription opioids are frequently crushed for snorting or extracted for IV use $[9 \bullet, 12]$. These types of formulations are designed to withstand physical pressure applied to pills, thus making users unable to create a fine powder for either snorting or IV abuse. Additionally, these formulations turn into a gel-like compound when dissolved in water or other solvents, thus making it difficult to extract for IV use. Examples of tamperresistant formulations include reformulated extended-release oxycodone (ERO), oxymorphone (Opana ER), and Tapentadol (Nucynta ER).

\section{Reformulated extended-release oxycodone}

Extended-release oxycodone was first introduced in 1996 and aggressively marketed as an effective pain reliever with substantially reduced addiction potential due to its long-acting pharmacologic properties. However, it quickly became the most widely abused prescription opioid in the USA [15]. As a result, extended-release oxycodone (ERO) was reformulated with tamper-resistant technology and released to market in August 2010.

Since its re-release, numerous studies have examined both its abuse potential and the actual post-marketing outcome regarding its abuse prevalence and overdose-related mortality rates. Extraction of the active compound from reformulated ERO is substantially more difficult [16], and in a study of recreational users $(N=30)$, it received the lowest ratings among all opioid products in terms of attractiveness, value, desirability, and likelihood of tampering [17]. In a pharmacokinetics study conducted in healthy controls, Perrino et al found that in contrast to the original formulation of oxycodone (Oxycontin), the crushed reformulated compound demonstrated a lower maximum plasma concentration as well as an increased time to reach maximum plasma concentration. As a result, when the reformulation was crushed, the user experienced a slowed oxycodone release, reduction in euphoric effects, and greater intranasal irritation [18].

Since release of the abuse-deterrent formulation of oxycodone, a number of studies have shown substantial reductions in the rates of oxycodone misuse and diversion. Based upon data from the Survey of Key Informants' Patients (SKIP) program of the Researched Abuse, Diversion and Addiction-Related Surveillance (RADARS) system, Cicero et al reported significant post-reformulation reductions in both (1) rates of identification of ERO as primary drug of choice 
and (2) past month ERO abuse in patients entering treatment; however, the prevalence of heroin use among respondents nearly doubled [19•]. In a later study based upon data from the National Addictions Vigilance Intervention and Prevention Program (NAVIPPRO), Butler et al. reported that non-oral abuse of reformulated ERO in individuals assessed for substance abuse treatment was $66 \%$ lower in comparison to previously reported rates of misuse of the original formulation ERO [20]. Further, Havens et al found in a sample of experienced ERO abusers in a rural Kentucky county $(N=189)$ that self-reported rates of past 30-day abuse of reformulated ERO were lower (any route $33 \%, 1.9$ days/ month; snorting $5 \%$, 0.2 days/month; injecting $0.5 \%,<0.1$ days/month) than those of oxycodone IR (any route $96 \%, 19.5$ days/month; snorting $70 \%$, 10.3 days/month; injecting $51 \%, 10.5 \%$ days/month) as well as retrospectively reported rates of abuse of the original formulation of ERO [21].

In addition to observed reductions in the rates of reformulated ERO misuse, the harms associated with ERO also appear to be decreased. Based upon data from the Poison Center Study and Drug Diversion programs of the RADARS System, Severtson et al reported that in the 18-month period following the release of reformulated ERO (October 2010 through March 2012), ERO abuse exposure calls to poison centers decreased $38 \%$, therapeutic errors decreased $24 \%$, and diversion reports decreased $53 \%$ [22]. In a separate study examining data from the National Poison Data System (NPDS), Coplan et al reported that following ERO reformulation, calls to poison centers related to abuse exposures decreased $36 \%$, therapeutic errors decreased $20 \%$, and accidental exposures decreased $39 \%$, while calls related to heroin and other single-entity (SE) oxycodone formulations either remained stable or were increased [23]. Based upon the manufacturer's pharmacovigilance database, Sessler et al found that ERO abuse-related overdose deaths (adjusted per 100,000 ERO prescriptions dispensed after the reformulation) decreased $86 \%$ from the year before to the third year after reformulation, while non-fatal ERO adverse events and reported ER morphine fatalities remained unchanged [24].

Not surprisingly, the reductions in rates of misuse and diversion of ERO have sparked additional clinical study of its underlying pharmacological mechanism, with evaluation of whether this method could be employed with other opioid compounds. Recently, a phase III clinical trial sponsored by Purdue Pharma LP of ER hydrocodone (hydrocodone bitartrate (HYD)), which utilizes an identical, polymer matrix chemical platform as ERO, was completed; however, results of this study have not yet been disseminated (NCT01400139 at clinicaltrial.gov). Altogether, the ERO formulation represents an effective strategy for reducing both nonmedical use of oxycodone and medical complications stemming from misuse.

\section{Extended-release oxymorphone (Opana ER)}

Extended-release oxymorphone (Opana ER, Endo Pharmaceuticals Inc.) is a crush-resistant formulation of oxymorphone embedded in hard polyethylene oxide (PEO), approved by FDA on Dec 9, 2011 and made commercially available in 2012. This reformulation, oxymorphone ER-PEO, has been shown to resist crushing by spoons, pill crushers, and hammers as well as resistance to extraction by a test battery of solvents [25]. In a study meant to assess the medication's ability to withstand tampering, Vosburg et al asked drug users to 
attempt preparation of reformulated oxymorphone according to their usual patterns, and then measured the resulting particle size and yield of active drug ingredient [26]. The investigators found that the oxymorphone ER-PEO was more difficult to crush into particles suitable for insufflation or injection, and $92 \%$ of participants reported unwillingness to insufflate and $84 \%$ unwilling to inject the tampered products. Despite these findings, however, there have been incidents of misuse of oxymorphone ER-PEO as well several reports of medical complications, such as stroke, seizures, and a thrombotic thrombocytopenic purpura-like illness when the medication is used intravenously [27-29].

\section{Extended-release tapentadol (Nucynta)}

ER tapentadol (Nucynta ${ }^{\circledR}$ ER, Ortho-McNeil-Janssen Pharmaceuticals, Inc.) is another formulation utilizing the polyethylene oxide (PEO) matrix. Vosburg et al demonstrated this new formulation had minimum yield of product when tampered with by experienced opioid-dependent individuals [30]. Of note, only $16-24 \%$ of participants were willing to use this medication by snorting in comparison to $100 \%$ of those who expressed willingness to use the original formulation of ER Oxycontin via the same method.

\section{Osmotic extended-release oral delivery system (OROS) hydromorphone (Exalgo)}

OROS hydromorphone (Exalgo ${ }^{\circledR}$, Mallinckrodt Pharmaceuticals, Inc.) was approved by the FDA in 2010 as a treatment for moderate to severe chronic pain of lasting duration, specifically for those in whom tolerance to opioids has already developed [31-33]. OROS technology consists of an osmotically active bilayer core enclosed in a semipermeable tablet shell membrane, which is considered as tamper-deterrent, because the tablet is difficult to crush and the active ingredient cannot be extracted for injection [34]. To date, no clinical studies regarding the abuse potential of OROS hydromorphone are available [35].

\section{Controlled-release oxycodone (Remoxy ER)}

Controlled-release oxycodone (Remoxy ER, CRO), a reformulation featuring a high-viscosity hard gelatin capsule, was designed to resist tampering and cannot be extracted with a needle [36]. Setnik et al demonstrated reduced drug liking and abuse potential when CRO, taken whole or chewed, was compared to orally administered oxycodone IR and crushed oxycodone ER [37]. Additionally, Butler et al reported an estimated pre-marketing attractiveness of CRO close to Talwin NX (pentozine combined with naloxone) and significantly different from ER oxycodone (OxyContin, Purdue Pharmac LP), Oxycodone/ acetaminophen, (Percocet, Endo Pharmaceuticals) and hydrocodone/ acetaminophen (Vicodin, Abbott Laboratories) [38]. However, the FDA declined to approve CRO in June 2011 [39].

\section{Controlled-release oxycodone/acetaminophen (Xartemis XR)}

Utilizing PEO technology, the first tamper-resistant oral combination medication, controlled-release oxycodone/acetaminophen (Xartemis XR, Mallinckrodt Pharmaceuticals, Inc.; CR OC/APAP), received FDA approval and was released in 2014 [40]. In phase I study, CR OC/APAP demonstrated less drug liking and 
delayed onset of subjective effects in comparison to intact immediate-release oxycodone/acetaminophen [41]. Importantly, when CR OC/APAP was crushed, a further delay in onset of subjective effects was observed. Interestingly, this formulation possesses both immediate- and extended-release properties, and it is this attribute which results in the delayed onset of action when the medication is crushed, since these portions of the medication are then combined [42].

\section{Other tamper-resistant formulations currently under development}

Egalet Corporation currently has under development two formulations of pain medication, a controlled-release morphine compound (Egalet 001) and a tamper-resistant oxycodone compound (Egalet 002), which utilize pharmacologic technology to resist common methods of abuse, such as crushing, snorting, dissolving in order to inject, and alcohol dose dumping [43]. Egalet 001 completed phase II clinical trials in 2008 (NCT00446069 at clinicaltrials.gov), and is currently undergoing phase III trial. From CIMA Labs, Inc., a new formulation of extended-release of hydrocodone using CIMA $^{\circledR}$ Abuse-Deterrence Technology is also in an active stage of development. This medication, which features granulated, polymer-coated hydrocodone molecules which are then compressed into tablets, are designed to control release of hydrocodone when taken orally and to further protect against release if the medication is crushed or taken with alcohol [44]. In phase I study, these hydrocodone extended-release tablets, even when pre-treated with high levels of polymer coating, demonstrated similar pharmacokinetics to immediaterelease hydrocodone, allowing for comparable pain relief while increasing tamper-resistance [45].

\section{Opioid switching}

There is strong evidence of the significant and immediate decline in misuse of tamper-resistant medications, such as reformulated extendedrelease oxycodone, as well as associated adverse outcomes; however, at the same time, there have been increasing reports of abuse of other opioids with greater tampering potential, such as heroin or buprenorphine [19•, 23, 25]. Buer et al reported in a small sample of individuals longitudinally followed for substance use $(N=25)$ that a shift from misuse of the original formulation of oxycodone (OxyContin ${ }^{\circledR}$ ) to misuse of immediate-release oxycodone formulations was observed following release of the reformulated extended-release oxycodone (ERO) [46]. In a larger, sentinel sample of 232,874 adults assessed for substance abuse treatment within NAVIPPRO surveillance system, the prevalence of abuse increased for all prescription opioids as a class as well as for ER opioids, with significantly greater abuse of ER oxymorphone and buprenorphine after the introduction of reformulated ERO in 2010, also indicating possible switching of the opioid of choice [47]. These findings suggest that replacement of a widely prescribed opioid formulation alone may have little impact on overall rates of opioid as a class, since without treatment, opioid-dependent individuals are likely to continue substance misuse unabated. 


\section{Abuse-deterrent formulations with aversive components}

The second type of abuse-deterrent mechanism of action is to add aversive components. The aversive ingredients in these formulations cause unpleasant, but not serious or fatal, reactions when people overtake the prescribed dose or use alternate, non-oral routes of administration. Examples include immediaterelease oxycodone containing niacin (Acurox ${ }^{\circledR}$, Acura Pharmaceuticals, Inc), immediate-release oxycodone with niacin-free aversive components (Oxecta ${ }^{\circledR}$, Pfizer, Inc.), and oxycodone/acetaminophen with aversive components (Acuracet ${ }^{\circledR}$, Acura Pharmaceuticals, Inc.). Although promising, the overall clinical utility and effectiveness of these medications is not yet entirely known. For example, these formulations may prevent misuse by reducing oral overtaking and non-oral use, but they might also limit the effectiveness of pain management when compliant patients require higher medication doses due to development of tolerance. Additionally, it is possible that the physical discomfort caused by the aversive components may not be severe enough to deter abuse in those with severe dependence. All the same, this particular mechanism represents an important and exciting advance in the pharmaceutical management of opioid misuse.

\section{Immediate-release oxycodone with aversive components}

Originally introduced by Acura Pharmaceuticals as oxycodone-niacin (Acurox)), this immediate-release oxycodone formulation containing niacin (vitamin $B_{3}$ ), caused a burning sensation in the nasal passage when crushed and snorted as well as uncomfortable flushing when the medication was overtaken orally [48]. However, the FDA declined to approve oxycodone-niacin in 2010, citing concerns regarding the adverse effects due to niacin; as a result, the medication was reformulated as an immediate-release with niacin-free aversive components (Oxecta ${ }^{\circledR}$, Pfizer Inc.), which ultimately received FDA approval in 2011 [49]. This approved medication, immediate-release oxycodone with inactive functional excipients (IRO-A), was found in pharmacokinetic study to have similar bioequivalence to both marketed immediate-release oxycodone (Roxicodone) and the IRO-A with niacin formulation, but lacked the flushing adverse effect observed with IRO-A with niacin [50]. In a randomized, doubleblind, active-controlled study in nondependent, recreational opioid users aged $18-55$ years $(N=40)$, Schoedel et al found that participants receiving crushed IRO-A tablets reported lower scores on drug liking and desire to take the drug again in comparison to those administered crushed IRO (Roxicodone) [51]. The technology utilized with this medication, known as Aversion ${ }^{\circledR}$, is currently being tested in the combination product, oxycodone/acetaminophen; however, there are no published clinical studies at this time [52].

\section{Opioid agonist/antagonist combination}

The third abuse-deterring mechanism is the addition of an opioid antagonist along with the opioid formulation. Within the medication, opioid antagonists can be sequestered and released only when tampering or use by non-oral route of administration occurs. 


\section{Extended-release morphine and sequestered naltrexone}

In the abuse-deterrent formulation of extended-release morphine and sequestered naltrexone (MS-sNT; Embeda ${ }^{\circledR}$, Pfizer Inc.), the ratio of morphine sulfate:naltrexone is $100: 4(20 \mathrm{mg} / 0.8 \mathrm{mg}$ as the lowest dose) [53]. When the medication is crushed or chewed, the sequestered antagonist is released from the core of the capsule, counteracting the euphoric effects of the opioid and even precipitating withdrawal symptoms, in some cases [54, 55]. Importantly, the naltrexone component remains inert if the medication is taken through the oral route and without tampering. In a single-center, randomized, doubleblind, crossover study of opioid-dependent males $(N=28)$, participants reported significantly less euphoria and drug liking when intravenously administered crushed MS-sNT in comparison to IV morphine alone [56]. Recently, the FDA approved updated labeling for the medication which specifically reflects the abuse-deterrent properties of the medication, and the product is slated to become commercially available in 2015 [57].

\section{Buprenorphine/naloxone and other buprenorphine formulations}

Used to treat opioid use disorders in Europe since 1996 and in the USA since 2003, buprenorphine/naloxone (Suboxone ${ }^{\circledR}$ ) carries the potential to become the first-line medication to treat opioid dependence due to its favorable side effect profile, reduced abuse potential and availability in office-based settings [58•]. This abuse-deterrent medication was originally formulated as the sublingually administered tablet combination of a high-affinity mu-opioid partial agonist and an opioid antagonist. Given the comparatively poorer oral bioavailability of naltrexone, when the tablet was taken as directed, the partial agonist effect of buprenorphine would predominate, sparing the patient from experiencing the antagonist effect [59]. However, with direct oral ingestion or crush/insufflation of the tablet, the naloxone effect would come to predominate, thus precipitating withdrawal [60]. Likewise, with water or solvent dissolution of the tablet for IM or IV use, naloxone could not be separated from buprenorphine, ensuring the antagonist effect would either diminish the euphoric effects or cause opioid withdrawal [61, 62]. Studies support the decreased addiction liability associated with buprenorphine/naloxone; for example, in a study performed in Finland, a country with significant rates of buprenorphine mono abuse, $80 \%$ of buprenorphine/naloxone abusers reported having a "bad" experience with the combined formulation in comparison to buprenorphine alone. The associated negative experience reduced its demand with the street price of combination tablets being less than half of that of buprenorphine alone [63].

Despite its lower abuse potential, both anecdotal reports and clinical case studies indicate that misuse and diversion of buprenorphine/naloxone for illicit purposes does occur $[64,65]$. Additionally, buprenorphine exposure rates among US children have continued to increase since its introduction. One recent epidemiologic study found that 13,600 exposures were recorded through the pharmacovigilance monitoring system, and approximately $36 \%$ of these exposures occurred in children under age 6 years [66]. In relation to these concerns regarding diversion, and in an attempt to increase treatment compliance, three newer formulations of the medication have been developed, (a) sublingual film, (b) buprenorphine depot injection, and (c) buprenorphine 
implant. The reformulated sublingual film, introduced in the US in 2010, has gained wider usage due to its faster dissolution on the oral submucosa as well as tamper-resistant packaging to reduce the likelihood of accidental exposures in children $[67,68]$. Importantly, in a recent, multi-site, double-blind, doubledummy parallel group trial of buprenorphine/naloxone patients $(N=92)$, researchers compared the film with the tablet formulation, and found the two preparations demonstrated comparable dose effects and clinical outcomes [69].

The depot formulation of buprenorphine (Norvex ${ }^{\mathrm{TM}}$ ) utilizes a biodegradable polymer microcapsule technology for subcutaneous injection of $58 \mathrm{mg}$ of buprenorphine mono for the treatment of opioid use disorder [70]. The injection provides an opioid blockade effect of approximately 6 weeks duration [70]. In a small double-blind, placebo-controlled, randomized clinical trial of participants with opioid use disorder $(N=15)$, depot buprenorphine demonstrated effectiveness in suppressing withdrawal symptoms and attenuated the effects of exogenous opioid challenge in comparison to placebo [71].

The buprenorphine implant (Probuphine ${ }^{\circledR}$, Titan Pharmaceuticals) delivers a constant, low level of medication for up to a 6-month time period. Utilizing a long-term drug delivery system, a small, solid "rod" made from a polymer matrix of ethylene vinyl acetate and the equivalent of $80 \mathrm{mg}$ of buprenorphine, the rod is placed subdermally and later removed at the end of the treatment period. Because of the matrix technology of the implant, it is difficult to retrieve the medication from the rod, discouraging patient attempts to remove the implant [72]. One open-label study and two randomized, placebo-controlled studies of the buprenorphine implant demonstrated its effectiveness in treating opioid dependence, with participants receiving the medication showing a higher percentage of opioid-free urine samples and minimal withdrawal symptoms almost comparable to those observed with sublingual buprenorphine [73-75]. However, long-term efficacy of these two formulations for maintenance therapy needs further investigation.

\section{Other strategies to reduce the prescription opioid epidemic}

Necessarily, in addition to the development of abuse-deterrent formulations, other factors, such as provider prescribing patterns, patient education, and access to substance abuse treatment, must be addressed in order to ensure a lasting impact upon prescription opioid misuse. An important first priority is to balance the availability of prescription opioids for pain management without increasing the supply of medications diverted for nonmedical use. In this regard, regulations and health policy have been shown to be influential factors $[76,77]$. Additionally, prescription monitoring programs have been associated with lower prescription volume [78], reductions in poison center intentional exposures and opioid treatment admission [79], and overdose mortality from prescription opioids [76]. However, there are concerns that prescription monitoring programs primarily result in a shift in prescribing practices, rather than decreased abuse rates $[80,81]$. Leftover medications have been shown to be a huge resource for prescription opioid abuse [82], and there is widespread unsafe storage and disposal of unused prescription opioids obtained from emergency departments [83], thus take-back programs for unused prescription medications need to be in place [84]. Responsible clinical practice in pain 
management and risk stratifications have been shown to be effective in preventing prescription opioid diversion and abuse [85-87]. Specialized, comprehensive pain rehabilitation programs utilizing a multidisciplinary approach and incorporating modalities such as behavioral therapy as well as physical and occupational therapies in conjunction with non-opioid pharmacological treatment have been found to be a cost effective strategy which could further reduce healthcare burden and improve patient functioning and quality of life $[88,89]$. Changes in policy and reimbursement strategies may help to incentivize further creation and widespread integration of these services and enhance their impact upon the prescription opioid epidemic by reducing both supply of and demand for pain medications. Lastly, increasing the access to substance abuse treatment will be crucial to curb the epidemic, and effective medication treatments, such as buprenorphine, need to be more widely disseminated.

\section{Conclusions and future steps}

The creation of a cadre of opioid formulations which effectively manage pain without adverse events or the potential for prescription opioid abuse potential would be ideal, but remains unlikely for the foreseeable future. Given current limitations, both pharmacological and non-pharmacological strategies are necessary to curb the prescription opioid epidemic. Newly developed abusedeterrent formulations may quickly decrease the prevalence of misuse of certain prescription opioids, as demonstrated in the example of OxyContin. However, these novel medications, including tamper-resistant formulations, formulations with aversive components, and formulations with opioid antagonists, cannot single-handedly cure the epidemic. Ultimately, the advent of compounds with decreased likelihood of abuse must be combined with public health and policy measures (i.e., prescription monitoring programs), patient and physician education, and increased addictions treatment services in order to create opportunities for widespread change.

\section{Acknowledgments}

This material is the result of work supported with resources and the use of facilities at the Michael E. DeBakey VA Medical Center.

\section{Compliance with Ethics Guidelines}

\section{Conflict of Interest}

Xiaofan Li declares that he has no conflict of interest. 
Daryl Shorter declares that he has no conflict of interest.

Thomas Kosten declares that he has no conflict of interest.

Human and Animal Rights and Informed Consent

This article does not contain any studies with human or animal subjects performed by any of the authors.

\section{References and Recommended Reading}

Papers of particular interest, published recently, have been highlighted as:

- Of importance

1. Center for Disease Control and Prevetion (CDC). Vital signs: overdoses of prescription opioid pain relievers-United States, 1999-2008. MMWR. 2011;60:1487-92.

2. Center for Disease Control and Prevetion (CDC). Emergency department visits involving nonmedical use of selected prescription drugs-United States, 2004-2008. MMWR. 2010;59:705-9.

3. http://www.samhsa.gov/data/sites/default/files/ NSDUH-DetTabsPDFWHTML2013/Web/PDFW/ NSDUH-DetTabsSect1peTabs11to18-2013.pdf. [cited December, 2014]; Available from:.

4. Zosel A, Bartelson BB, Bailey E, Lowenstein S, Dart R. Characterization of adolescent prescription drug abuse and misuse using the Researched Abuse Diversion and Addiction-related Surveillance (RADARS ${ }^{\circledR}$ ) System. J Am Acad Child Adolesc Psychiatry. 2013;52:196204.e2.

5. Brandt SA, Taverna EC, Hallock RM. A survey of nonmedical use of tranquilizers, stimulants, and pain relievers among college students: patterns of use among users and factors related to abstinence in non-users. Drug Alcohol Depend. 2014;143:272-6.

6. Schepis TS, Krishnan-Sarin S. Sources of prescriptions for misuse by adolescents: differences in sex, ethnicity, and severity of misuse in a population-based study. J Am Acad Child Adolesc Psychiatry. 2009;48:828-36.

7. Shei A, Rice JB, Kirson NY, Bodnar K, Birnbaum HG, Holly P, Ben-Joseph R. Sources of prescription opioids among diagnosed opioid abusers. Curr Med Res Opin. Published online: February 24, 2015. doi:10.1185/ 03007995.2015.1016607.

8. McCabe SE, West BT, Boyd CJ. Leftover prescription opioids and nonmedical use among high school seniors: a multi-cohort national study. J Adolesc Health. 2013;52:480-5.

9.• Butler SF, Black RA, Cassidy TA, Dailey TM, Budman $\mathrm{SH}$. Abuse risks and routes of administration of different prescription opioid compounds and formulations. Harm Reduct J. 2011;8:29.

This article compiles data on the abuse risk and routes of administration of 11 commonly prescribed opioid formulations, including hydrocodone, IR and ER oxycodone, methadone, IR and ER morphine, hydromorphone, IR and ER fentanyl, IR and ER oxymorphone. It specifically examined the adjusted risk of each substance based upon their prescription volume. The authors' findings speak to the abuse potential for these compounds in order to facilitate specific approaches to address their abuse.

10. Butler SF, Budman SH, Licari A, Cassidy TA, Lioy K, Dickinson J, et al. National addictions vigilance intervention and prevention program (NAVIPPRO): a realtime, product-specific, public health surveillance system for monitoring prescription drug abuse.

Pharmacoepidemiol Drug Saf. 2008;17:1142-54.

11. Hays LR. A profile of OxyContin addiction. J Addict Dis. 2004;23:1-9.

12. Katz N, Dart RC, Bailey E, Trudeau J, Osgood E, Paillard F. Tampering with prescription opioids: nature and extent of the problem, health consequences, and solutions. Am J Drug Alcohol Abuse. 2011;37:205-17.

13. Butler SF, Black RA, Serrano JM, Wood ME, Budman $\mathrm{SH}$. Characteristics of prescription opioid abusers in treatment: prescription opioid use history, age, use patterns, and functional severity. J Opioid Manag. 2009;6:239-41.

14. Young AM, Havens JR. Transition from first illicit drug use to first injection drug use among rural Appalachian drug users: a cross-sectional comparison and retrospective survival analysis. Addiction. 2012;107:58796.

15. Van Zee A. The promotion and marketing of Oxycontin: commercial triumph, public health tragedy. Am J Public Health. 2009;99:221-7.

16. Cone EJ, Giordano J, Weingarten B. An iterative model for in vitro laboratory assessment of tamper deterrent formulations. Drug Alcohol Depend. 2013;131:100-5.

17. Sellers EM, Perrino PJ, Colucci SV, Harris SC. Attractiveness of reformulated OxyContin ${ }^{\circledR}$ tablets: assessing comparative preferences and tampering potential. J Psychopharmacol. 2013;27:808-16.

18. Perrino PJ, Colucci SV, Apseloff G, Harris SC. Pharmacokinetics, tolerability, and safety of intranasal administration of reformulated OxyContin ${ }^{\circledR}$ tablets 
compared with original OxyContin ${ }^{\circledR}$ tablets in healthy adults. Clin Drug Investig. 2013;33:441-9.

19.• Cicero TJ, Ellis MS, Surratt HL. Effect of abuse-deterrent formulation of OxyContin. N Engl J Med. 2012;367:187-9.

This is an important article that raised the concern of replacement of OxyContin by other opioids and heroin. It also mentions the importance of non-pharmacological strategies for reducing prescription opioid epidemic.

20. Butler SF, Cassidy TA, Chilcoat H, Black RA, Landau C, Budman SH, et al. Abuse rates and routes of administration of reformulated extended-release oxycodone: initial findings from a sentinel surveillance sample of individuals assessed for substance abuse treatment. J Pain. 2013;14:351-8.

21. Havens JR, Leukefeld CG, DeVeaugh-Geiss AM, Coplan $\mathrm{P}$, Chilcoat HD. The impact of a reformulation of extended-release oxycodone designed to deter abuse in a sample of prescription opioid abusers. Drug Alcohol Depend. 2014;139:9-17.

22. Severtson SG, Bartelson BB, Davis JM, Munoz A, Schneider MF, Chilcoat $\mathrm{H}$, et al. Reduced abuse, therapeutic errors, and diversion following reformulation of extended-release oxycodone in 2010. J Pain.

2013;14:1122-30.

23. Coplan PM, Kale H, Sandstrom L, Landau C, Chilcoat HD. Changes in oxycodone and heroin exposures in the National Poison Data System after introduction of extended-release oxycodone with abuse-deterrent characteristics. Pharmacoepidemiol Drug Saf. 2013;22:1274-82.

24. Sessler NE, Downing JM, Kale H, Chilcoat HD, Baumgartner TF, Coplan PM. Reductions in reported deaths following the introduction of extended-release oxycodone (OxyContin) with an abuse-deterrent formulation. Pharmacoepidemiol Drug Saf.

2014;23:1238-46.

25. Bartholomaeus JH, Arkenau-Maric E, Galia E. Opioid extended-release tablets with improved tamperresistant properties. Expert Opin Drug Deliv. 2012;9:879-91.

26. Vosburg SK, Jones JD, Manubay JM, Ashworth JB, Benedek IH, Comer SD. Assessment of a formulation designed to be crush-resistant in prescription opioid abusers. Drug Alcohol Depend. 2012;126:206-15.

27. Center for Disease Control and Prevetion (CDC). Thrombotic thrombocytopenic purpura (TTP)-like illness associated with intravenous Opana ER abuseTennessee, 2012. MMWR. 2013;62:1-4.

28. Kapila A, Chhabra L, Chaubey VK, Summers J. Opana ER abuse and thrombotic thrombocytopenic purpura (TTP)-like illness: a rising risk factor in illicit drug users. BMJ Case Rep 2014; 2014.

29. Ambruzs JM, Serrell PB, Rahim N, Larsen CP. Thrombotic microangiopathy and acute kidney injury associated with intravenous abuse of an oral extended-release formulation of oxymorphone hydrochloride: kidney biopsy findings and report of 3 cases. Am J Kidney Dis. 2014;63:1022-6.
30. Vosburg SK, Jones JD, Manubay JM, Ashworth JB, Shapiro DY, Comer SD. A comparison among tapentadol tamper-resistant formulations (TRF) and OxyContin ${ }^{\circledR}$ (non-TRF) in prescription opioid abusers. Addiction. 2013;108:1095-106.

31. Hanna M. Thipphawong J,118 Study Group. A randomized, double-blind comparison of OROS ${ }^{\circledR}$ hydromorphone and controlled-release morphine for the control of chronic cancer pain. BMC Palliat Care. 2008;7:17.

32. Hanna M, Tuca A, Thipphawong J. An open-label, 1year extension of the long-term safety and efficacy of once-daily OROS ${ }^{\circledR}$ hydromorphone in patients with chronic cancer pain. BMC Palliat Care. 2009;8:14.

33. Gardner-Nix J, Mercadante S. The role of OROS hydromorphone in the management of cancer pain. Pain Pract. 2010;10:72-7.

34. Palangio M, Northfelt DW, Portenoy RK, Brookoff D, Doyle Jr RT, Dornseif BE, et al. Dose conversion and titration with a novel, once-daily, OROS osmotic technology, extended-release hydromorphone formulation in the treatment of chronic malignant or nonmalignant pain. J Pain Symptom Manage. 2002;23:355-68.

35. Moorman-Li R, Motycka CA, Inge LD, Congdon JM, Hobson S, Pokropski B. A review of abuse-deterrent opioids for chronic nonmalignant pain. P T. 2012;37:412-8.

36. Raffa RB, Pergolizzi Jr JV. Opioid formulations designed to resist/deter abuse. Drugs. 2010;70:1657-75.

37. Setnik B, Roland CL, Cleveland JM, Webster L. The abuse potential of Remoxy ${ }^{\circledR}$, an extended-release formulation of oxycodone, compared with immediateand extended-release oxycodone. Pain Med. 2011;12:618-31.

38. Butler SF, Black R, Grimes Serrano JM, Folensbee L, Chang A, Katz N. Estimating attractiveness for abuse of a not-yet-marketed "abuse-deterrent" prescription opioid formulation. Pain Med. 2010;11:81-91.

39. FDA Complete Response Letter Received for Remoxy. Jun 24, 2011. Available at: http://www.drugs.com/nda/ remoxy_110624.html. Accessed January 8, 2015.

40. Xartemis XR receives FDA approval: May reduce opioid abuse. March 28, 2014. Available at: http:// formularyjournal.modernmedicine.com/formularyjournal/content/tags/acetaminophen/xartemis-xrreceives-fda-approval-may-reduce-opioid-abu. Accessed January 8, 2015.

41. Morton T, Kostenbader K, Montgomery J, Devarakonda $\mathrm{K}$, Barrett T, Webster L. Comparison of subjective effects of extended-release versus immediate-release oxycodone/acetaminophen tablets in healthy nondependent recreational users of prescription opioids: a randomized trial. Postgrad Med. 2014;126:20-32.

42. Singla N, A randomized, double-blind, placebocontrolled, Phase 3 study of the safety and analgesic efficacy of MNK-795 controlled-release oxycodone/ acetaminophen tablets (CR OC/APAP) in an acute pain model. Oral poster presentation at Pain Week 2013. 
September 4-7, 2013. Available at: http://www.lotuscr. com/lotus-pdf/Mallinckrodt-MNK795-

PainWeek2013-OralPresentation_101.pdf.

43. Egalet Product Pipeline. 2015. Available at: http:// www.egalet.com/products-and-pipeline/pipeline/. Accessed January 8, 2015.

44. Darwish M, Yang R, Tracewell W, Robertson Jr P, Bond M. Single- and multiple-dose pharmacokinetics of a hydrochloride bitartrate extended-release tablet formulated with abuse-deterrence technology in healthy, naltrexone-blocked volunteers. Clin Ther. 2014. doi:10.1016/j.clinthera.2014.11.014.

45. Darwish M, Bond M, Tracewell W, Robertson Jr P, Yang R. Pharmacokinetics of hydrocodone extended-release tablets formulated with different levels of coating to achieve abuse deterrence compared with a hydrocodone immediate-release/acetaminophen tablet in healthy subjects. Clin Drug Investig. 2015;35:13-22.

46. Buer LM, Havens JR, Leukefeld C. Does the new formulation of OxyContin(R) deter misuse? A qualitative analysis. Subst Use Misuse. 2014;49:770-4.

47. Cassidy TA, DasMahapatra P, Black RA, Wieman MS, Butler SF. Changes in prevalence of prescription opioid abuse after introduction of an abuse-deterrent opioid formulation. Pain Med. 2014;15:440-51.

48. Daniels SE, Spivey R, Golf M, Clark FJ, Robson M, Diamond EL, Zimmerman JC, Singla S. Acurox ${ }^{\circledR}$ (Oxycodone $\mathrm{HCl} /$ niacin) tablets for the treatment of acute, moderate to severe pain following bunionectomy surgery in adult patients. Poster presented at American Pain Society Annual Meeting. May 7-9, 2009. Available at: http://www.lotuscr.com/lotus-pdf/Acura-AcuroxAPS2009-Poster.pdf. Accessed: January 8, 2015.

49. Feuerstein A. Pfizer, Acura Painkiller Approved by FDA. June 20, 2011. Available at: http://www.thestreet.com/ story/11157620/1/pfizer-acura-painkiller-approvedby-fda.html. Accessed: January 8, 2015.

50. Leibowitz MT, Zamora CA, Brzeczko AW, Stark JG. A single-dose, 3-way crossover pharmacokinetic comparison between immediate-release oxycodone hydrochloride with aversion technology (IRO-A, Oxecta), IRO-a with niacin, and oxycodone hydrochloride (Roxicodone) in healthy adults under fasting conditions. Am J Ther. 2014;21:99-105.

51. Schoedel KA, Rolleri RL, Faulknor JY, Pixton GC, Chen $\mathrm{N}$, Bass A, et al. Assessing subjective and physiologic effects following intranasal administration of a new formulation of immediate release oxycodone $\mathrm{HCl}$ $\left(\right.$ Oxecta $\left.{ }^{\mathrm{TM}}\right)$ tablets in nondependent recreational opioid users. J Opioid Manag. 2012;8:315-27.

52. Acuracet tablets. Acura. Available at: http:// acurapharm.com/products/acuracet-tablets/. Accessed: January 8, 2015

53. Physician Prescribing Information: EMBEDA - morphine sulfate and naltrexone hydrochloride capsule, extended release. Pfizer Laboratories Div. Pfizer Inc. Available at: http://labeling.pfizer.com/ShowLabeling. aspx?id=694. Accessed: January 9, 2015.
54. Ruan X, Chen T, Gudin J, Couch JP, Chiravuri S. Acute opioid withdrawal precipitated by ingestion of crushed Embeda (morphine extended release with sequestered naltrexone): case report and the focused review of the literature. J Opioid Manag. 2010;6:300-3.

55. Setnik B, Roland CL, Goli V, Sommerville K, Webster L. A clinical trial to determine if corelease of morphine and naltrexone from crushed extended-release capsules induces withdrawal in opioid-dependent patients: a descriptive analysis of six patients. J Opioid Manag. 2013;9:139-50.

56. Webster LR, Johnson FK, Stauffer J, Setnik B, Ciric S. Impact of intravenous naltrexone on intravenous morphine-induced high, drug liking, and euphoric effects in experienced, nondependent male opioid users. Drugs R\&D. 2011;11:259-75.

57. FDA approves abuse deterrent labeling for EMBEDA ${ }^{\circledR}$ (morphine sulfate and naltrexone hydrochloride) extended-release (ER) capsules CII. Pfizer. Available at: http://www.pfizer.com/news/press-release/pressrelease-detail/fda_approves_abuse_deterrent_ labeling_for_embeda_morphine_sulfate_and_ naltrexone_hydrochloride_extended_release_er_ capsules_cii. Accessed: January 9, 2015.

58. Mattick RP, Breen C, Kimber J, Davoli M. Buprenorphine maintenance versus placebo or methadone maintenance for opioid dependence. Cochrane Database Syst Rev. 2014;2:CD002207.

This Cochrane review evaluated 31 randomized controlled trials on the efficacy of buprenorphine in treating opioid addiction, compared to methadone and placebo. It is a thorough review and critical evaluation on this topic.

59. Chiang CN, Hawks RL. Pharmacokinetics of the combination tablet of buprenorphine and naloxone. Drug Alcohol Depend. 2003;70:S39-47.

60. Middleton LS, Nuzzo PA, Lofwall MR, Moody DE, Walsh SL. The pharmacodynamic and pharmacokinetic profile of intranasal crushed buprenorphine and buprenorphine/naloxone tablets in opioid abusers. Addiction. 2011;106:1460-73.

61. Fudala PJ, Yu E, Macfadden W, Boardman C, Chiang $\mathrm{CN}$. Effects of buprenorphine and naloxone in morphine-stabilized opioid addicts. Drug Alcohol Depend. 1998;50:1-8.

62. Preston KL, Bigelow GE, Liebson IA. Buprenorphine and naloxone alone and in combination in opioiddependent humans. Psychopharmacology (Berl). 1988;94:484-90.

63. Alho H, Sinclair D, Vuori E, Holopainen A. Abuse liability of buprenorphine-naloxone tablets in untreated IV drug users. Drug Alcohol Depend. 2007;88:75-8.

64. Furst RT. Suboxone misuse along the opiate maintenance treatment pathway. J Addict Dis. 2013;32:5367.

65. Smith MY, Bailey JE, Woody GE, Kleber HD. Abuse of buprenorphine in the United States: 2003-2005. J Addict Dis. 2007;26:107-11. 
66. Soyka M. Buprenorphine and buprenorphine/ naloxone intoxication in children-how strong is the risk? Curr Drug Abuse Rev. 2013;6:6370 .

67. Das NG, Das SK. Development of mucoadhesive dosage forms of buprenorphine for sublingual drug delivery. Drug Deliv. 2004;11:89-95.

68. Strain EC, Harrison JA, Bigelow GE. Induction of opioid-dependent individuals onto buprenorphine and buprenorphine/naloxone soluble films. Clin Pharmacol Ther. 2011;89:443-9.

69. Lintzeris N, Leung SY, Dunlop AJ, Larance B, White N, Rivas GR, et al. A randomised controlled trial of sublingual buprenorphine-naloxone film versus tablets in the management of opioid dependence. Drug Alcohol Depend. 2013;131:119-26.

70. Sobel BF, Sigmon SC, Walsh SL, Johnson RE, Liebson IA, Nuwayser ES, et al. Open-label trial of an injection depot formulation of buprenorphine in opioid detoxification. Drug Alcohol Depend. 2004;73:11-22.

71. Sigmon SC, Wong CJ, Chausmer AL, Liebson IA, Bigelow GE. Evaluation of an injection depot formulation of buprenorphine: placebo comparison. Addiction. 2004;99:1439-49.

72. Ling W, Mooney L, Zhao M, Nielsen S, Torrington M, Miotto K. Selective review and commentary on emerging pharmacotherapies for opioid addiction. Subst Abuse Rehabil. 2011;2:181-8.

73. White J, Bell J, Saunders JB, Williamson P, Makowska $M$, Farquharson A, et al. Open-label dose-finding trial of buprenorphine implants (Probuphine) for treatment of heroin dependence. Drug Alcohol Depend. 2009; 103:37-43.

74. Ling W. Buprenorphine implant for opioid addiction. Pain Manag. 2012;2:345-50.

75. Rosenthal RN, Ling W, Casadonte P, Vocci F, Bailey GL, Kampman K, et al. Buprenorphine implants for treatment of opioid dependence: randomized comparison to placebo and sublingual buprenorphine/naloxone. Addiction. 2013;108:2141-9.

76. Johnson H, Paulozzi L, Porucznik C, Mack K, Herter B. Decline in drug overdose deaths after state policy changes-Florida, 2010-2012. MMWR. 2014;63:56974 .

77. Surratt HL, O'Grady C, Kurtz SP, Stivers Y, Cicero TJ, Dart RC, et al. Reductions in prescription opioid diversion following recent legislative interventions in Florida. Pharmacoepidemiol Drug Saf. 2014;23:314-20.
78. Curtis LH, Stoddard J, Radeva JI, Hutchison S, Dans PE, Wright A, et al. Geographic variation in the prescription of schedule II opioid analgesics among outpatients in the United States. Health Serv Res. 2006;41:837-55.

79. Reifler LM, Droz D, Bailey JE, Schnoll SH, Fant R, Dart $\mathrm{RC}$, et al. Do prescription monitoring programs impact state trends in opioid abuse/misuse? Pain Med. 2012;13:434-42.

80. Wang J, Christo PJ. The influence of prescription monitoring programs on chronic pain management. Pain Physician. 2009;12:507-15.

81. Fischer B, Bibby M, Bouchard M. The global diversion of pharmaceutical drugsnon-medical use and diversion of psychotropic prescription drugs in North America: a review of sourcing routes and control measures. Addiction. 2010;105:2062-70.

82. McCabe SE, West BT, Boyd CJ. Leftover prescription opioids and nonmedical use among high school seniors: a multi-cohort national study. J Adolesc Health. 2013;52:480-5.

83. Tanabe P, Paice JA, Stancati J, Fleming M. How do emergency department patients store and dispose of opioids after discharge? A pilot study. J Emerg Nurs. 2012;38:273-9.

84. Fain KM, Alexander GC. Disposing of medicines safely. Am J Public Health. 2014;104:e2-3.

85. Manchikanti L, Manchukonda R, Damron KS, Brandon D, McManus CD, Cash K. Does adherence monitoring reduce controlled substance abuse in chronic pain patients? Pain Physician. 2006;9:57-60.

86. Manchikanti L, Manchukonda R, Pampati V, Damron KS, Brandon DE, Cash KA, et al. Does random urine drug testing reduce illicit drug use in chronic pain patients receiving opioids? Pain Physician. 2006;9:123-9.

87. Bujold E, Huff J, Staton EW, Pace WD. Improving use of narcotics for nonmalignant chronic pain: a lesson from Community Care of North Carolina. J Opioid Manag. 2012;8:363-7.

88. Gatchel RJ, Okifuji A. Evidence-based scientific data documenting the treatment effectiveness of comprehensive pain programs for chronic nonmalignant pain. J Pain. 2006;7:779-93.

89. Sletten CD, Kurklinsky S, Chinburapa V, Ghazi S. Economic analysis of a comprehensive pain rehabilitation program: a collaboration between Florida Blue and Mayo Clinic Florida. Pain Med. Published online: February 3, 2015. DOI: 10.1111/pme.12679. 